\title{
Review Article
}

\section{Metal speciation and microbial growth-the hard (and soft) facts}

\author{
Martin N. Hughes ${ }^{*}$ and Robert K. Poole ${ }^{2}$ \\ Department of Chemistry ${ }^{1}$ and Microbial Physiology Research Group, ${ }^{2}$ King's College London, Campden Hill Road, \\ London $W 87 A H, U K$
}

Micro-organisms require certain metallic elements for growth and function (Hughes \& Poole, 1989). These include, for example, the bulk elements potassium and magnesium, and trace elements such as manganese, iron, copper, zinc and molybdenum. Essential metals are shown in Fig. 1, the Periodic Table. The need for these essential metals is, or should be, acknowledged in the composition of growth media. However, higher concentrations of these metals, and the heavy metals such as silver, cadmium, mercury, tin and lead (Fig. 1), may be toxic. In any study of the biological effects of either essential or toxic metals it is imperative that full account be taken of the speciation or chemical form(s) of the metal ion in the growth medium, in the organisms' environment, and in experimental media such as buffers; the bioavailability, and hence reactivity, of the metal is critically dependent upon its speciation (Bernhard et al., 1986; Morrison et al., 1989). Unfortunately it appears that little attention is sometimes given to these matters, and that this has led to some invalid and misleading conclusions in the microbiological literature. In this review it is intended to survey the factors that control the speciation of metal ions in media, to summarize methods for establishing the speciation of metal ions in solution and to suggest some simple guidelines for estimating the bioavailability of metal ions in media. Some commonly-used media will be assessed in the light of these comments and attention drawn to errors that have resulted from a failure to recognize the importance of metal speciation.

A recent and topical example will serve to illustrate the importance of speciation effects and the ease with which they are overlooked. It has been suggested in both the scientific and popular press that levels of atmospheric carbon dioxide could be reduced by 'sowing' the ocean with tons of iron filings to boost growth of marine algae (Davies, 1990; Martin et al., 1990). Little mention has been made of the problems of maintaining the iron in a form which is bioavailable. Significantly, Hutner (1972) cites much earlier work, which demonstrated that the fertility of the Sargasso Sea is limited only by the amounts of chelating agents present, which in turn determines the amount of iron which is bioavailable; merely adding EDTA to samples of the water significantly enhanced algal growth.

\section{Chemical speciation: factors that affect the availability of metal ions in growth media}

An essential 'metal' is usually added to the growth medium as a simple metal salt, often as the aquacomplex $\left[\mathrm{M}\left(\mathrm{H}_{2} \mathrm{O}\right)_{6}\right] \mathbf{X}_{n}$ (where $\mathbf{M}^{n+}=$ metal ion, $\mathbf{X}^{-}=$anion, and the coordination number is 6). However, the metal ion may well be present in the complete growth medium in several different forms depending upon the chemical properties and concentrations of the anions and chelating agents present in solution and on the $\mathrm{pH}$ value. Analysis for the concentration of the metal ion in the medium by techniques such as atomic absorption or emission spectroscopy will give the total concentration and will not reveal the way in which the metal ion is distributed in its various species. These individual species may be coordination complexes differing in the identity of the ligands in the coordination sphere, the overall charge (positive, neutral or negative), the oxidation state of the metal, lipophilicity, and affinity towards binding sites on cell surfaces. Only one of these species, perhaps representing a minor fraction of the total metal ion concentration, may be responsible for the biological effect exerted by the metal. Ideally it would be valuable to know the concentration and reactivity of all species of the metal ion present in the medium. Some factors that may determine bioavailability are summarized below prior to a fuller discussion.

\section{Charge on the complex}

Neutral complexes are more likely than charged ones to be transported across biological membranes by nonspecific routes, and so will exert toxic effects more 


\begin{tabular}{|c|c|c|c|c|c|c|c|c|c|c|c|c|c|c|c|c|}
\hline $\mathrm{Li}$ & $\mathrm{Be}$ & & & & & & & & & & & B & C & $\mathbf{N}$ & o & $\mathbf{F}$ \\
\hline $\mathbf{N a}$ & Mg & & & & & & & & & & & $A l$ & $\mathrm{Si}$ & $\mathbf{P}$ & $\mathbf{S}$ & $\mathrm{Cl}$ \\
\hline $\mathbf{K}$ & $\mathbf{C a}$ & $\underline{\mathbf{s} \boldsymbol{c}}$ & $\mathrm{Ti}$ & $\mathbf{v}$ & $\mathbf{C r}$ & $\mathbf{M n}$ & $\mathbf{F e}$ & Co & $\mathbf{N i}$ & Cu & Zn & $\underline{\mathrm{Ga}}$ & $\mathrm{Ge}$ & $A s$ & Se & $\mathrm{Br}$ \\
\hline$\underline{R} \mathbf{b}$ & $\mathbf{S r}$ & $\mathbf{Y}$ & $\mathrm{Zr}_{\mathbf{r}}$ & $\mathrm{Nb}$ & Mo & $\mathrm{Tc}$ & $\underline{\mathbf{R u}}$ & $\underline{\mathbf{R h}}$ & $\underline{\mathbf{P d}}$ & $A g$ & $C d$ & In & $S n$ & $S b$ & $T e$ & I \\
\hline T. & $\mathrm{Ba}$ & $\mathbf{L a}$ & $\mathrm{Hf}$ & Ta & $\underline{\mathbf{w}}$ & $\mathrm{Re}$ & Os & Ir & $\underline{\mathbf{P t}}$ & $\underline{\mathrm{Au}}$ & $\mathrm{Hg}$ & $T l$ & $P b$ & $\mathrm{Bi}$ & Po & At \\
\hline
\end{tabular}

Fig. 1. The Periodic Table of the Elements showing metals and metalloids of interest to inorganic microbiologists. Essential metals or metalloids are shown in bold, toxic metals are italicized and metals used as drugs, antimicrobial agents and probes are underlined. Hydrogen, helium, the lanthanides and the actinides are omitted.

readily. For example, at neutral $\mathrm{pH}$ values the noncharged aquamonocarbonato complexes of $\mathrm{Cu}(\mathrm{II})$ and $\mathrm{Zn}(\mathrm{II})$ are more toxic than the charged aquacomplexes formed at lower $\mathrm{pH}$ values and the anionic biscarbonato complexes formed at higher $\mathrm{pH}$ values (Stumm \& Bilinski, 1972).

\section{Complexation}

This effect is probably the most significant overall in assessing the bioavailability of metal ions. The bioavailability or toxicity of a metal ion will vary considerably with the chemical constitution of the medium and hence the availability of ligands. Many studies on metal toxicity are of little comparative value because they have been carried out using a 'rich' medium or one which contains a specific ligand that strongly complexes the metal ion under study. The toxicity of the metal ion will be greatly reduced under these conditions as it will be strongly complexed. This explains why Tetrahymena pyriformis can tolerate a 100 -fold higher concentration of $\mathrm{Cu}(\mathrm{II})$ in a rich organic medium than in a defined one (Nilsson, 1981), why addition of yeast extract to cultures of Aerobacter aerogenes (Klebsiella pneumoniae) protects the bacteria from the usual toxic effects of $\mathrm{Cu}(\mathrm{II})$ (MacLeod et al., 1967), and why yeast extract can alleviate the toxic effects of $\mathrm{Ag}(\mathrm{I})$ on the oxidation of $\mathrm{Fe}(\mathrm{II})$ by Thiobacillus ferrooxidans (Tuovinen et al., 1985). Bird et al. (1985) have also drawn attention to the effect of growth medium on the chemical speciation of $\mathrm{Cu}(\mathrm{II})$, and the implication for toxicity studies.

Inorganic anions can also affect the bioavailability of metal ions through complexation, possibly by their effect on the charge on the complex, as described above for the carbonate ligand. Examples of the effects brought about by such changes of speciation include the protective effect of high concentrations of $\mathrm{NaCl}(2-4 \mathrm{M})$ on the toxic effects of $\mathrm{CdCl}_{2}$ by forming anionic chloro complexes (Onishi et al., 1984) and the enhanced uptake of germanium by algae at high $\mathrm{pH}$ (Yanagimoto et al., 1983) probably due to the formation of anionic hydroxogermanium species.

\section{Precipitation}

This is particularly relevant to toxicity studies, as salts of the heavy elements are often of low solubility. Phosphates in particular are readily precipitated out of solution. The insolubility of cadmium and other phosphates and even of silver chloride does not seem always to have been appreciated; finely divided precipitates are not easily detected in the turbid media of growing cultures! This has led to claims for organisms with remarkably high tolerances to cadmium or silver, when in fact the concentration of the toxic cation in solution has been negligible. Trace essential metal ions may also be precipitated or co-precipitated as phosphates.

A further example of precipitation is associated with metal ions such as $\mathrm{Cu}(\mathrm{II})$ and $\mathrm{Fe}(\mathrm{III})$, which although usually present as aqua cations in acidic aqueous solution, may also be precipitated as hydroxides or oxides at higher $\mathrm{pH}$ values. Certain organisms can utilize precipitates as a source of metals, either by abstracting the metal ion directly or by producing ligands that complex and solubilize the metal ion. For example, the siderophores solubilize iron(III) hydroxide. However, problems of precipitation may be overcome by designing a medium either with replacements for anions that cause precipitation or with appropriate complexing ligands. Thus, phosphate may be replaced by glycerophosphate, while addition of citrate will ensure that $\mathrm{Cu}(\mathrm{II})$ and $\mathrm{Fe}$ (III) remain soluble at around $\mathrm{pH}$ 7. Note, however, that the bioavailability of these metal ions is then decreased compared to that of aqua complexes.

\section{Changes in speciation during growth}

Speciation of metal ions may change during growth of the organism. Examples in the literature include precipitation of metal ions as oxalates or phosphates, precipitation resulting from a change in $\mathrm{pH}$, and complexation by a ligand synthesized by the cell. In one case, the speciation of $\mathrm{Cu}(\mathrm{II})$ changed during growth of Pseudomonas testosteroni from a $1: 3 \mathrm{Cu}: \mathrm{NH}_{3}$ complex to a $1: 2$ 
species due to the decrease in the medium of the concentration of the ammonium ion as it was utilized by the organism (A. Ahmad, M. N. Hughes, A. M. Nobar and R. K. Poole, unpublished work).

\section{Loss of metal species by binding to surfaces}

A further general complication should be noted. Certain metal ions (for example Sn(II) species) are readily lost from solution by adsorption to the wall of the reaction vessel. This phenomenon is only significant when carrying out experiments at micromolar concentrations of metal species. It may be alleviated by using plastic vessels.

\section{Problems of precipitation: quantitative aspects}

Some anions present in growth media may cause the precipitation of metal ions, particularly the heavy metal ions. Inspection of tables of solubilities of inorganic compounds (for example, Weast, 1978) shows that many common metal phosphates are insoluble in water (such as those of $\mathrm{Zn}(\mathrm{II}), \mathrm{Fe}(\mathrm{II})$, and $\mathrm{Cd}(\mathrm{II})$ ) or only slightly soluble in water $(\mathrm{Fe}(\mathrm{III}))$. However, the solubility data for sparingly soluble compounds must be considered in terms of the effects of common ions and $\mathrm{pH}$ upon solubility.

\section{Solubility product and the common ion effect}

For sparingly soluble salts, those whose solubility is less than $0.01 \mathrm{M}$, the product of the molar concentrations of the ions is constant at a fixed temperature. This constant, the 'solubility product', may be calculated from the solubility of the compound in aqueous solution. For example, the solubility of silver chloride is $1.05 \times 10^{-5} \mathrm{M}$ : thus the solubility product is $1.1 \times 10^{-10} \mathrm{M}^{2}$.

$$
\begin{aligned}
\mathrm{MX} & \rightleftharpoons \mathrm{M}^{+}+\mathrm{X}^{-} \quad K_{\mathrm{sp}} \rightleftharpoons\left[\mathrm{M}^{+}\right] \times\left[\mathrm{X}^{-}\right] \\
\mathrm{M}_{p} \mathrm{X}_{q} & \rightleftharpoons \mathrm{pM}^{q+}+q \mathrm{X}^{p-} K_{\mathrm{sp}} \rightleftharpoons\left[\mathrm{M}^{q+}\right]^{p} \times\left[\mathrm{X}^{p-}\right]^{q}
\end{aligned}
$$

Precipitation of the sparingly soluble salt takes place when the product of the concentrations of the ions exceeds the value of the solubility product. In growth media, the concentration of the anion may be much greater than that of the metal ion due to the presence of another electrolyte containing the anion. The product of the concentrations of the ions $\mathrm{M}^{+}$and $\mathrm{X}^{-}$in solution may then exceed the solubility product, so that precipitation of the solid takes place readily. This common ion effect is illustrated by the decreased solubility of silver chloride in the presence of added chloride. The solubility product of $\mathrm{AgCl}$ is $1 \cdot 1 \times 10^{-10} \mathrm{M}^{2}$. In the presence of $1 \mathrm{mM}$ chloride ion, the maximum concentration of $\mathrm{Ag}^{+}$in solution is $1.1 \times 10^{-7} \mathrm{M}$, compared with $1.05 \times 10^{-5} \mathrm{M}$ in the ab- sence of added chloride.

$$
K_{\text {sp }}=1 \cdot 1 \times 10^{-10}=\left[\mathrm{Ag}^{+}\right] \times\left[1 \times 10^{-3}\right]
$$

The solubility of $\mathrm{AgCl}$ has decreased by a factor of 100 due to the presence of only $1 \mathrm{~mm}-\mathrm{NaCl}$.

Several other factors affect solubilities. Complex formation will decrease the concentration of the metal ion and so allow more solid to pass into solution. Increase in acidity may also increase solubility if the anion involved in precipitation is the anion of a weak acid. Protonation of the anion leads to a decrease in its concentration, which allows further dissolution of solid. This factor is important for the salts of acids such as phosphoric acid and arsenic acid.

Some studies on the interactions of micro-organisms with silver will now be discussed to illustrate the uncertainties that can arise when precipitation is not fully considered. Silver ions, $\mathrm{Ag}^{+}$, are well known to be extremely toxic to micro-organisms (Trevors, 1987), although this toxicity is alleviated through complexing of $\mathrm{Ag}^{+}$to cellular and medium components, by precipitation of silver compounds and by reduction to the metal (Belly \& Kydd, 1982). Of the 300 p.p.m. of silver nitrate added to nutrient broth, only 3 p.p.b. of $\mathrm{Ag}^{+}$was detected (Belly \& Kydd, 1982). Pooley (1982) has shown that Thiobacillus ferrooxidans catalysing the bio-oxidation of sulphidic silver ores accumulated silver sulphide particles on cell surfaces. Significantly, $\mathrm{Ag}_{2} \mathrm{~S}$ is highly insoluble, with a solubility product of $1.6 \times 10^{-49} \mathrm{M}^{3}$. Ehrlich (1987), in an investigation of the bioleaching of silver from a mixed sulphide ore, prepared an inoculum of $T$ : ferrooxidans by cultivation in $9 \mathrm{~K}$ medium containing $10^{-4} \mathrm{M} \mathrm{AgNO}_{3}{ }^{\prime}$. The $9 \mathrm{~K}$ medium (Silverman \& Lundgren, 1959) contains $0.1 \mathrm{~g} \mathrm{KCll}^{-1}$, and is $1.34 \mathrm{~mm}$ in chloride. From the solubility product of $\mathrm{AgCl}$ it may be calculated that the maximum concentration of $\mathrm{Ag}^{+}$ under these conditions is $8.21 \times 10^{-8} \mathrm{M}$, implying that the added $\mathrm{Ag}^{+}$would have been precipitated. This medium contains ammonium sulphate at $3 \mathrm{~g} \mathrm{l}^{-1}$, giving a concentration of ammonium ion of $0.0454 \mathrm{M}$. However the $\mathrm{p} K_{\mathrm{a}}$ for $\mathrm{NH}_{4}^{+}$is $9 \cdot 26$. At the $\mathrm{pH}$ of the medium (2.0) the concentration of $\mathrm{NH}_{3}$ will be $2.5 \times 10^{-9} \mathrm{M}$, and will be insufficient to solubilize the $\mathrm{AgCl}$ via complexation.

Sugio et al. (1981) reported that silver-ion-resistant $T$. ferrooxidans grew in $9 \mathrm{~K}$ medium at $5 \times 10^{-4} \mathrm{M}-\mathrm{AgNO}_{3}$. From their analysis, they claimed that the silver was present as insoluble species equivalent to $4.6 \times 10^{-4} \mathrm{M}$ and soluble species at $2.78 \times 10^{-5} \mathrm{M}$. It is clearly unrealistic to claim that the organism is resistant to $5 \times 10^{-4} \mathrm{M}$ silver! It should be noted that the amount of soluble $\mathrm{Ag}^{+}$in the $9 \mathrm{~K}$ medium can be calculated as $8.21 \times 10^{-8} \mathrm{M}$, which is very different from the reported value for soluble silver. There may be problems with analysis. Their suggestion that reduced glutathione 
(GSH) was involved in the resistance mechanism may be incorrect, as the GSH could function by complexing the $\mathrm{Ag}^{+}$and removing it from the cell wall. A medium for studying the effect of silver ions on Escherichia coli has been described by Ghandour et al. (1988).

\section{Hydrolysis and precipitation of cations}

Speciation of metal cations in aqueous solution changes with change of $\mathrm{pH}$, and may lead to precipitation of hydroxides or oxides, unless ligands are present to complex the cation. In aqueous solution, divalent metal ions undergo hydrolysis to give hydroxo complexes, followed by dimerization through the formation of oxo bridges and finally giving precipitates.

$$
\begin{gathered}
\mathrm{M}\left(\mathrm{H}_{2} \mathrm{O}\right)_{6}^{2+} \rightleftharpoons \mathrm{M}\left(\mathrm{H}_{2} \mathrm{O}\right)_{5}(\mathrm{OH})^{+}+\mathrm{H}^{+} \\
\mathrm{M}\left(\mathrm{H}_{2} \mathrm{O}\right)_{5}(\mathrm{OH})^{+} \rightleftharpoons \mathrm{M}\left(\mathrm{H}_{2} \mathrm{O}\right)_{4}(\mathrm{OH})_{2}+\mathrm{H}^{+} \\
2 \mathrm{M}\left(\mathrm{H}_{2} \mathrm{O}\right)_{5}(\mathrm{OH})^{+} \rightleftharpoons\left(\mathrm{H}_{2} \mathrm{O}\right)_{5} \mathrm{MOM}\left(\mathrm{H}_{2} \mathrm{O}\right)_{5}^{2+}+\mathrm{H}_{2} \mathrm{O}
\end{gathered}
$$

At higher $\mathrm{pH}$ values these precipitates will redissolve giving anionic hydroxometallate complexes (e.g. $\left.\mathrm{Zn}(\mathrm{OH})_{4}^{2-}\right)$ (Baes \& Mesmer, 1976).

The $\mathrm{p} K_{\mathrm{a}}$ values of the aqua cations of $\mathrm{Ni}(\mathrm{II}), \mathrm{Zn}(\mathrm{II})$, $\mathrm{Cu}(\mathrm{II})$ and $\mathrm{Cd}(\mathrm{II})$ are $9.9,9.0,8.0$ and 9.9 respectively. Precipitation usually begins to occur about $2-3 \mathrm{pH}$ units below the $\mathrm{p} K_{\mathrm{a}}$ value of the aqua complex, provided that the concentration of metal ion is sufficient. As the $\mathrm{pH}$ of solutions of the divalent transition metal ions is raised precipitation occurs in the order of the Lewis acidity of the metal ion, taking place first for the smallest cation, namely $\mathrm{Cu}(\mathrm{II})$. The stronger the Lewis acid the more acidic is the coordinated water molecule. Precipitation effects are thus more important for the aqua cations $\mathrm{M}\left(\mathrm{H}_{2} \mathrm{O}\right)_{6}^{3+}$ such as $\mathrm{Fe}^{3+}$ and $\mathrm{Al}^{3+}$, and will occur at lower $\mathrm{pH}$ values. Precipitation of $\mathrm{Fe}$ (III) begins at $\mathrm{pH}$ values 2-3.

\section{The complexing power of ligands and the likely speciation of metal ions}

It is possible to formulate some general conclusions about the speciation of metal ions in growth media from a consideration of the chemical properties and concentrations of the metal ions and ligands present. The ability of a metal ion to complex a ligand depends upon its polarizing power, that is upon the charge/radius ratio of the cation. A cation of high polarizing power is 'seen' by the ligand as a centre of high density of positive charge, and strong interaction takes place between the metal ion and the ligand. Such a metal ion is described as a strong Lewis acid. Ionic size decreases from left to right across the Periodic Table (Fig. 1). This means that the alkali metal cations $\mathrm{Na}^{+}$and $\mathrm{K}^{+}$interact very weakly with ligands, and can be disregarded from a speciation point of view. The doubly-charged cations $\mathrm{Mg}^{2+}$ and $\mathrm{Ca}^{2+}$ interact more strongly with ligands than do the cations $\mathrm{Na}^{+}$and $\mathrm{K}^{+}$, but weakly compared to the transition metal ions. In general, for small ligands, $\mathrm{Mg}^{2+}$ binds more strongly than does $\mathrm{Ca}^{2+}$, but this can be reversed. The ionic radii of the transition metal ions decrease in size down to $\mathrm{Cu}^{2+}$, with an increase to $\mathrm{Zn}^{2+}$. Thus, in broad terms, the strength of interaction between divalent transition metal ions and ligands increases from left to right across the first transition series, $\mathrm{Mn}(\mathrm{II})<\mathrm{Fe}(\mathrm{II})<$ $\mathrm{Co}(\mathrm{II})<\mathrm{Ni}(\mathrm{II})<\mathrm{Cu}(\mathrm{II})>\mathrm{Zn}(\mathrm{II})$. Cations such as $\mathrm{Fe}^{3+}$ bind more strongly still, in view of their greater polarizing power (i.e. Lewis acidity).

The binding of some of the toxic metal ions to ligands cannot be compared straightforwardly with that of the essential metal ions in terms of polarizing power. The cations $\mathrm{K}^{+}$and $\mathrm{Tl}^{+}$have similar ionic radii and the same charge, but $\mathrm{Tl}^{+}$often interacts about a thousand times more strongly with ligands than does $\mathrm{K}^{+}$. This situation arises because $\mathrm{Tl}^{+}$has more electrons than does $\mathrm{K}^{+}$and is therefore polarized more easily. The thallium cation is described as 'soft' while the potassium cation is 'hard'. Hard cations are usually small, of high charge and cannot be polarized. Table 1 classifies metal ions of biological interest as hard, soft or intermediate and also includes information on simple ligands (Pearson, 1963). It can be seen that oxygen-donor ligands are hard and sulphurdonors are soft. As a general rule, hard ligands prefer to bind to hard metals and soft ligands prefer to bind to soft metal ions. But, if both hard and soft metal ions are present, then the soft metal ions will often win the competition for binding ligands, and will displace essential metal ions from their sites. Inspection of Table 1 shows that essential metal ions are hard or borderline hard, while the common toxic metals, with the exception of aluminium, are soft. The information in Table 1 provides a useful indication of likely combinations of metals and ligands. These conclusions are summarized in

\begin{tabular}{|c|c|c|c|c|c|}
\hline \multicolumn{3}{|c|}{ Acids } & \multicolumn{3}{|c|}{ Bases } \\
\hline Hard & Borderline & Soft & Hard & Borderline & Soft \\
\hline $\begin{array}{l}\mathrm{Na}^{+} \\
\mathrm{K}^{+} \\
\mathrm{Rb}^{+} \\
\mathrm{Mg}^{2+} \\
\mathrm{Ca}^{2+} \\
\mathrm{Mn}^{2+} \\
\mathrm{Fe}^{3+} \\
\mathrm{Al}^{3+} \\
\mathrm{Co}^{3+}\end{array}$ & $\begin{array}{l}\mathrm{Fe}^{2+} \\
\mathrm{Co}^{2+} \\
\mathrm{Ni}^{2+} \\
\mathrm{Cu}^{2+} \\
\mathrm{Zn}^{2+}\end{array}$ & $\begin{array}{l}\mathrm{Cu}^{+} \\
\mathrm{Pb}^{2+} \\
\mathrm{Cd}^{2+} \\
\mathrm{Hg}^{2+} \\
\mathrm{Tl}^{+} \\
\mathrm{Ag}^{+} \\
\mathrm{Au}(\mathrm{I}) \\
\mathrm{Sn}(\mathrm{II})\end{array}$ & $\begin{array}{l}\mathrm{H}_{2} \mathrm{O} \\
\mathrm{ROH} \\
-\mathrm{CO}_{2}^{-} \\
\mathrm{NH}_{3} \\
\mathrm{RNH}_{2} \\
\text { Porphyrin } \\
\mathrm{Cl}^{-} \\
\mathrm{PO}_{4}^{3-} \\
\mathrm{SO}_{4}^{2-}\end{array}$ & Pyridine & $\begin{array}{l}\mathrm{CN}^{-} \\
\mathrm{RSH}^{-} \\
\mathrm{R}_{2} \mathrm{~S} \\
\mathrm{~S}_{2} \mathrm{O}_{3}^{2-}\end{array}$ \\
\hline
\end{tabular}
Table 2, where the preferences of metal ions for donor

Table 1. Hard and soft acids and bases 
Table 2. Preferences of metal ions for ligand donor groups

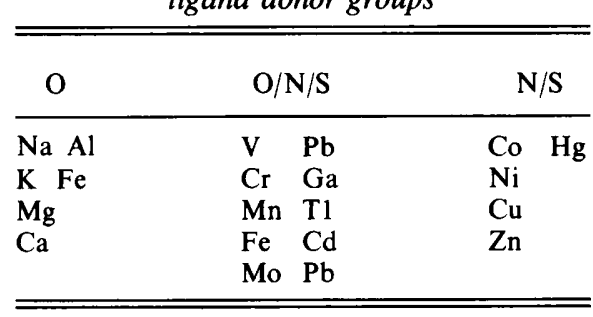

atoms are shown. A knowledge of the polarizing power of the cations will allow further conclusions to be drawn, as this will show, for example, which of the divalent transition metal ions present in a medium will win competitions for binding sites (this will normally be $\mathrm{Cu}$ (II), the strongest Lewis acid).

The interaction of metal ions and ligands can be described quantitatively by the use of formation constants. Indeed it is possible for the detailed speciation of metal ions in media to be calculated using formation constant data.

Consider the reversible interaction of a metal ion with a monodentate ligand (a ligand with only one donor atom). A series of stepwise equilibria exist for the formation of metal-ligand complexes of stoicheiometry $1: 1,1: 2,1: 3$ up to $1: N$, where $N$ is the maximum coordination number of the metal ion. Each of these steps can be described by an equilibrium constant (the formation constant), as shown below (charges and water molecules are omitted for simplicity).

$$
\begin{aligned}
\mathrm{M}+\mathrm{L} \rightleftharpoons \mathrm{ML} & K_{1}=[\mathrm{ML}] /[\mathrm{M}][\mathrm{L}] \\
\mathrm{ML}+\mathrm{L} \rightleftharpoons \mathrm{ML}_{2} & K_{2}=\left[\mathrm{ML}_{2}\right] /[\mathrm{ML}][\mathrm{L}] \\
\mathrm{ML}_{2}+\mathrm{L} \rightleftharpoons \mathrm{ML}_{3} & K_{3}=\left[\mathrm{ML}_{3}\right] /\left[\mathrm{ML}_{2}\right][\mathrm{L}] \\
\mathrm{ML}_{(N-1)}+\mathrm{L} \rightleftharpoons \mathrm{ML}_{N} & K_{N}=\left[\mathrm{ML}_{N}\right] /\left[\mathrm{ML}_{(N-1)}\right][\mathrm{L}]
\end{aligned}
$$

These equilibria can also be described in terms of overall formation constants, the two types of formation constant being related by $\beta_{N}=K_{1} \times K_{2} \times K_{3} \times \ldots K_{N}$.

$$
\begin{array}{ll}
\mathrm{M}+\mathrm{L} \rightleftharpoons \mathrm{ML} & \beta_{1}=[\mathrm{ML}] /[\mathrm{M}][\mathrm{L}] \\
\mathrm{M}+2 \mathrm{~L} \rightleftharpoons \mathrm{ML}_{2} & \beta_{2}=\left[\mathrm{ML}_{2}\right] /[\mathrm{M}][\mathrm{L}]^{2} \\
\mathrm{M}+3 \mathrm{~L} \rightleftharpoons \mathrm{ML}_{3} & \beta_{3}=\left[\mathrm{ML}_{3}\right][\mathrm{M}][\mathrm{L}]^{3}
\end{array}
$$

Compilations of formation constants for a wide range of metals and ligands are available (Sillen \& Martell, 1971). These are usually determined at fixed temperature and ionic strengths. The greater the value of the formation constant, the higher is the affinity of the metal ion for the ligand. Inspection of formation constant data will show which ligand out of those available in the medium will complex the metal. Alternatively, the data will show which metal ion will bind a particular ligand. These conclusions will depend upon the concentrations of metal and ligand, as a high concentration of a weakly binding ligand may be able to complex a metal ion in the presence of a low concentration of a strongly binding ligand. Under such conditions calculations should be carried out. Selected formation constants are shown in Table 3 for metal ions of microbiological interest. It is clear that

\begin{tabular}{|c|c|c|c|c|c|c|c|c|c|c|c|c|c|c|c|c|c|}
\hline \multirow[b]{2}{*}{ Ligand } & \multicolumn{17}{|c|}{$\log$ formation constant $\left(K_{1}\right)$} \\
\hline & $\mathrm{Na}^{+}$ & $\mathbf{K}^{+}$ & $\mathbf{M g}^{2+}$ & $\mathrm{Ca}^{2+}$ & $\mathrm{Mn}^{2+}$ & $\mathrm{Fe}^{2+}$ & $\mathrm{Fe}^{3+}$ & $\mathrm{Co}^{2+}$ & $\mathrm{Ni}^{2+}$ & $\mathrm{Cu}^{2+}$ & $\mathrm{Cu}^{+}$ & $\mathrm{Zn}^{2+}$ & $\mathrm{T}^{+}$ & $\mathrm{Ag}^{+}$ & $\mathrm{Al}^{3+}$ & $\mathrm{Cd}^{2+}$ & $\mathrm{Pb}^{2+}$ \\
\hline Glycine & & & 3.44 & 1.38 & 3.44 & $4 \cdot 3$ & & $5 \cdot 23$ & 5.77 & 8.62 & & 5.52 & & 3.5 & & $4 \cdot 8$ & $9 \cdot 12$ \\
\hline Cysteine & & & & & $4 \cdot 11$ & $6 \cdot 2$ & & $9 \cdot 33$ & & & $19 \cdot 2$ & 9.86 & & & & & $12 \cdot 2$ \\
\hline Aspartate & & & 2.43 & 1.60 & 3.74 & & & 5.94 & $7 \cdot 12$ & 8.57 & & $5 \cdot 84$ & & & & & \\
\hline Histidine* & & & & & $7 \cdot 74$ & $9 \cdot 3$ & & 13.9 & 15.9 & $18 \cdot 3$ & & $12 \cdot 9$ & & & & $11 \cdot 1$ & \\
\hline Glutamate & & & 1.9 & 2.05 & $3 \cdot 3$ & $4 \cdot 6$ & & 5.06 & 5.90 & 7.85 & & 5.45 & & & & & \\
\hline Citrate & & & $3 \cdot 6$ & $3 \cdot 3$ & 3.7 & $4 \cdot 4$ & $11 \cdot 4$ & 5.0 & & 5.9 & & $5 \cdot 0$ & & & $8 \cdot 0$ & & $6 \cdot 5$ \\
\hline Polyphosphate & & & $3 \cdot 0$ & $3 \cdot 2$ & $5 \cdot 5^{*}$ & 3.0 & $6 \cdot 5^{*}$ & $3 \cdot 0$ & & $5 \cdot 5$ & & $6 \cdot 0^{*}$ & 1.69 & & & & \\
\hline EDTA & 1.7 & 1.0 & $9 \cdot 12$ & $11 \cdot 0$ & 14.0 & 13.9 & $25 \cdot 1$ & $16 \cdot 2$ & $18 \cdot 6$ & $18 \cdot 8$ & & $16 \cdot 3$ & 5.84 & & 16 & $16 \cdot 6$ & $18 \cdot 3$ \\
\hline MES & & & 0.8 & 0.7 & 0.7 & & & & & & & & & & & & \\
\hline NTA & $2 \cdot 1$ & 1.0 & $7 \cdot 0$ & $6 \cdot 4$ & $7 \cdot 4$ & $8 \cdot 8$ & 15.9 & $10 \cdot 6$ & & $12 \cdot 8$ & & $10 \cdot 5$ & $4 \cdot 4$ & & & & $11 \cdot 8$ \\
\hline Glycylglycine & & & 0.8 & 0.8 & $1 \cdot 7$ & & & & & 5.8 & & & & & & & \\
\hline $\begin{array}{l}\text { 8-Hydroxy- } \\
\text { quinoline }\end{array}$ & & & $12 \cdot 0$ & $13 \cdot 2$ & $13 \cdot 5$ & $15 \cdot 0$ & $26 \cdot 3$ & $13 \cdot 9$ & $15 \cdot 2$ & $25 \cdot 4$ & & $17 \cdot 1$ & & & & & $10 \cdot 6$ \\
\hline $\begin{array}{l}\text { Thioglycollic } \\
\text { acid }\end{array}$ & & & & & & $10 \cdot 9$ & & & & & $14 \cdot 4$ & & & & & 15 & 15 \\
\hline
\end{tabular}
$\mathrm{Cu}$ (II) binds most strongly of all the divalent transition metal ions: it complexes glycine with approximately a thousand-fold greater affinity than does $\mathrm{Zn}$ (II). However, the data also show that $\mathrm{Cu}(\mathrm{II})$ cannot compete with

Table 3. Formation constants for metals and ligands of microbiological interest

Values are taken from Sillen \& Martell (1971).

* Values of $\beta_{2}$. 
$\mathrm{Fe}(\mathrm{III})$, the conclusion reached earlier on the basis of polarizing power. The data also illustrate how the relative affinity of $\mathrm{Mg}^{2+}$ and $\mathrm{Ca}^{2+}$ for ligands can vary depending upon the nature of the ligand. Formation constants for complexes of the divalent transition metal cations with nitrogen donor ligands increase in the series $\mathrm{Mn}$ (II) $<\mathrm{Fe}$ (II) $<\mathrm{Co}(\mathrm{II})<\mathrm{Ni}(\mathrm{II})<\mathrm{Cu}(\mathrm{II})>\mathrm{Zn}$ (II) . This sequence, discussed earlier, is the Irving-Williams series.

Metal ions compete with protons for sites on ligands. Ligands are often weak acids $\mathrm{H}_{n} \mathrm{~L}$ and complex as the anionic species. An increase in acidity will cause the ligand anion to be protonated and so lead to an increase in the concentration of the free metal ion. This effect will depend upon the $\mathrm{p} K_{\mathrm{a}}$ value of the ligand, and so competition for a metal ion by two ligands at a fixed $\mathrm{pH}$ value could well be determined by their $\mathrm{p} K_{\mathrm{a}}$ values. Complexation will be favoured by lower $\mathrm{p} K_{\mathrm{a}}$ values.

An important measurement in the context of speciation is the concentration of free metal ion (i.e. uncomplexed, usually defined as $\mathrm{pM}=-\log [\mathrm{M}])$. It is a relatively simple matter to calculate this when only one ligand is present: this would allow, for example, a comparison of the concentrations of free metal ion in two media containing different ligands.

When the metal ion is in excess and the ligand binds strongly, then $\left[\mathrm{M}_{\mathrm{f}}\right]=\left[\mathrm{M}_{\mathrm{t}}\right]-\left[\mathrm{L}_{\mathrm{t}}\right]$, where $\mathrm{f}=$ free and $t=$ total. If the ligand is in excess and is not protonated under the $\mathrm{pH}$ conditions of the experiment, then $\mathrm{L}_{\mathrm{t}}=\mathrm{ML}+\mathrm{L},[\mathrm{ML}] \sim\left[\mathrm{M}_{\mathrm{t}}\right]$ and the calculation is also straightforward.

$$
\begin{gathered}
K_{1}=[\mathrm{ML}] /[\mathrm{M}][\mathrm{L}]=\left[\mathrm{M}_{\mathrm{t}}\right] /[\mathrm{M}]\left[\mathrm{L}_{\mathrm{t}}-\mathrm{M}_{\mathrm{t}}\right] \\
\mathrm{pM}=-\log [\mathrm{M}]=\log K_{1}+\log \left(\left[\mathrm{L}_{\mathrm{t}}-\mathrm{M}_{\mathrm{t}}\right] /\left[\mathrm{M}_{\mathrm{t}}\right]\right)
\end{gathered}
$$

If protonation of the ligand has to be considered, the calculation is more complex, as $\mathrm{L}_{\mathrm{t}}=\mathrm{ML}+\mathrm{L}+\mathrm{HL}+$ $\mathrm{H}_{2} \mathrm{~L}+\ldots \mathrm{H}_{\mathrm{m}} \mathrm{L}$ (charges not included). An additional factor has to be introduced to allow for the concentration of protonated ligand species, which will be unable to combine with the metal. This can be calculated at any $\mathrm{pH}$ value knowing the $\mathrm{p} K_{\mathrm{a}}$ values for the ligand.

The effect of additional ligands in the medium must also be considered. If the formation constants for their complexation with a metal ion are similar, then the ligands will compete for the metal, which will be distributed among the two ligands. Competition between two metals for a particular ligand cannot be assessed readily from formation constant data if other ligands are present. One of the two metal ions may be bound to a much greater extent than the other by a second ligand; its free concentration is effectively reduced and it loses the competition which it may have been expected to win on a simple comparison of formation constants (Ringbom, 1963). Such complications emphasize the difficulties of calculating the speciation of a metal ion in complex media and hence the need for physical methods to study speciation.

\section{Methods for determining speciation}

The measurement of the concentrations of individual chemical species is a much more difficult exercise than the determination of total metal concentration. Concentrations of some metal species may be very low (perhaps down to nanomolar), and the nature of the samples may change with time. In extreme cases, metal-ligand systems may take days to come to equilibrium. Furthermore, the metabolic activity of the micro-organism may result in the modification of the distribution of species, with the production of volatile species or with new metal complexes being formed by complexation with ligands secreted by the cell. Ideally measurements of speciation by instrumental methods should be related to assays for biological activity, whether it be to study the toxicity or essential functions of a metal.

Experimental methods for determination of chemical speciation must involve either techniques that allow the simultaneous analysis of a number of species or the use of a chromatographic procedure to separate species followed by analysis of fractions (Bernhard et al., 1986; Duffield \& Williams, 1989). Such analysis of fractions could involve atomic absorption analysis for the metal, which will not distinguish between the fractions in a chemical sense, or techniques that can distinguish between different species and characterize them as unique entities. It is possible that some species may not be detected in these procedures. It is essential, therefore, that the total concentration of the metal in the sample of medium be determined, and that a mass balance should be attempted with the sum of the individual species. Failure to achieve a balance indicates that some species have not been detected. Unfortunately, determination of the total metal content itself may be unreliable, whether due to interferences or to poor technique. Other complications could result from changes in speciation with time. Many metal complexes are labile, with the metal-ligand bonds breaking and reforming rapidly. Ideally the metal-ligand bond should not be broken during the time needed for analysis or under the conditions of the determination. Organometallic compounds (with a metal-carbon bond) are a particular problem.

It is clear that determination of speciation can be a research exercise in its own right, although determination of oxidation state speciation is usually straightforward, and other methods may give information on some components of the system fairly readily. However, it is unrealistic to assume that major speciation studies can be 
carried out routinely, and it is therefore important that researchers are able to make general judgements on the bioavailability of metal ions in the media used in a particular investigation.

Some experimental approaches to the study of metal ion speciation are discussed in the following paragraphs.

\section{In situ methods}

These methods avoid disturbing the reaction system, but are not always particularly sensitive. Often one species only will be analysed for. A number of spectroscopic methods are useful. For transition metal complexes, the $\mathrm{d}-\mathrm{d}$ absorptions in the electronic spectrum will give information about the geometry of the species and some information about the ligand environment around the metal centre (Hughes \& Poole, 1989), as the wavelength of the absorption is sensitive to the ligands (the spectrochemical series). The major problem with the use of $d-d$ spectroscopy is the lack of intensity of the $d-d$ absorptions, molar absorptivities lying in the range 10$100 \mathrm{~m}^{-1} \mathrm{~cm}^{-1}$. Charge-transfer bands, usually in the UV, are also sensitive to the ligand and are much more intense. ESR techniques are particularly valuable for distinguishing paramagnetic species but will also give information about the ligands coordinated to the paramagnetic metal. Resonance Raman and FTIR spectroscopy yield information about metal speciation. The Raman technique is the more useful as it can be used more readily for aqueous solutions, since the water molecule does not absorb strongly in the Raman spectrum. Raman spectra of complexes at concentrations in the range $10^{-4}-10^{-6} \mathrm{M}$ can be determined under favourable conditions.

Electrochemical methods (Lund, 1986) also allow the determination of metal species in media. Ion-selective electrodes may be used to determine the concentration of free metal ion in solution, with a detection limit around $10^{-6} \mathrm{M}$. A copper-selective electrode has been used to determine the concentration of free copper in studies on the toxicity of copper towards algae (Sunda \& Lewis, 1978). Toxicity was related to the concentration of free copper and not to the total copper concentration. This does not exclude, however, toxic effects also being due to species such as $\mathrm{Cu}(\mathrm{OH})^{+}$whose concentration will be directly proportional to that of the free copper at a fixed $\mathrm{pH}$ value. To distinguish between these two possibilities, experiments will also have to be carried out at a different $\mathrm{pH}$ value (Guy \& Ross-Kean, 1980). Zevenhuizen et al. (1979) have used a $\mathrm{Cu}(\mathrm{II})$-specific electrode to construct a useful graph illustrating the dependency of $\mathrm{pCu}$ on the total $\mathrm{Cu}$ (II) added to solutions of potential complexing agents. In $0.5 \%$ phosphate buffer at $\mathrm{pH} 7$, copper(II) is complexed and maintained in a soluble complex at metal concentrations up to 2 p.p.m. At higher concentrations of $\mathrm{Cu}$ (II), insoluble copper(II) phosphate is precipitated. The addition of sodium potassium tartrate allowed added $\mathrm{Cu}$ (II) to remain in solution up to 63 p.p.m.

Polarographic (usually differential pulse polarography) and voltammetric techniques give the concentration of free metal ion and of complexes which are easily reduced. Differential pulse polarography has detection limits around $10^{-7} \mathrm{M}$. The polarogram allows the determination of the concentration of the species being reduced, while the 'half-wave potential' is characteristic of the species, as the redox potential of the complex will vary with the ligands present. Stripping voltammetry is a particularly valuable method for the study of metal speciation. It has better sensitivity and detection limits. One approach to studying the binding properties of a medium would be to titrate the medium with a solution of the metal and record voltammograms after each addition. This would allow the estimation of the metal-complexing properties of the medium as a response would be obtained only when free metal ions or easily reducible complexes were present in solution (Lund, 1986). The binding of metal ions to microbial cell surfaces can also be determined by these techniques since added metal ions would not be detected until metalbinding sites on cell surfaces were saturated and free metal ions were present in solution (I. Savvaidis, M. N. Hughes \& R. R. Poole, unpublished work).

\section{Separation and analysis}

These approaches largely involve the use of ion chromatography coupled to some type of detection system, such as UV-visible spectroscopy, conductivity and other electrochemical methods, atomic absorption or emission spectroscopy, and mass spectrometry. Krull (1986) has critically reviewed these methods.

\section{Computer simulation}

In theory, speciation of metal ions in microbiological media can be characterized by computer simulation studies, based upon formation constant data for the metals and ligands present in the medium. Such strategies have been applied to more complex biological fluids, such as human blood plasma (May \& Williams, 1981). These calculations apply to systems in thermodynamic equilibria and do not take into account any slow reactions taking place in the medium or microbial transformations of metallic species.

\section{Questions to be asked about growth media}

\section{Ligands}

Are strongly-complexing ligands present in the medium? 
If in doubt look up tables of formation constants. Compare concentrations of the ligand with that of the metal. Is there sufficient ligand to complex all the metal? Will neutral complexes be formed? Is the ligand likely to complex strongly enough to make the metal unavailable to the cell? Will the ligands be attacked by the organisms or undergo chemical decomposition under the growth conditions? EDTA appears to be resistant to microbial attack (Pirt, 1975) but will undergo photochemical decomposition over extended times, and should not be used in media for growing algae under intense illumination.

\section{Buffers}

Will buffers complex the metal ion? These may well be present at concentrations higher than other potential ligands.

\section{Precipitation}

Are the metals likely to precipitate at $\mathrm{pH} 6$ upwards as hydroxides and/or oxides? Is there the need for a chelating agent such as EDTA to maintain solubility? If so, note the effects on the bioavailability of the metal. Consider selecting a ligand of lower affinity for the metal ion. The metal must be bound strongly enough to remain soluble but weakly enough to avoid dramatic effects on its bioavailability.

\section{Anions}

Are anions present that may precipitate metal ions or affect speciation? Phosphate, sulphate, arsenate and chloride could all cause precipitation of cations (and cause co-precipitation of other essential trace elements) or affect bioavailability (e.g. $\mathrm{Zn}(\mathrm{II}), \mathrm{Cd}(\mathrm{II})$ ). If the inclusion of inorganic phosphate in the medium gives precipitates, glycerophosphate should be considered as an alternative phosphate source (e.g. Poole et al., 1989). Glycerophosphate is hydrolysed during autoclaving and so must be filter-sterilized.

\section{Antagonistic relationships}

Are there possibilities of antagonistic relationships between cations or between anions in the growth medium? Literature examples include sulphate and molybdate, phosphate and arsenate, and $\mathrm{Ag}^{+}$and $\mathrm{Cu}^{2+}$ (Hughes \& Poole, 1989; Ghandour et al., 1988). The soft toxic cations often exert toxic effects by competing successfully with essential elements.

\section{A look at growth media}

Hutners (1972) oft-cited review of microbial nutrition made the important point that inspection of catalogues of commercial media for cell cultures indicates a prevailing inadequacy in respect to trace elements, ... Trace elements beside iron are seldom included and chelating agents, as such, are omitted. Hence the media are buffered, in respect to transitional metals, only by the weak chelation lent by histidine and other amino acids'. Pirt (1975) has drawn attention to the requirement that metal buffers (i.e. chelating agents) in culture medium should not be metabolized. In his formulation of a chemically defined medium designed to yield biomass [of Aerobacter aerogenes (Klebsiella pneumoniae)] at up to $10 \mathrm{~g}$ dry biomass $1^{-1}$ in aerobic culture, the amount of EDTA included is 1 mol EDTA per mol magnesium plus metals other than alkali metal ions. Some other recipes for bacteriological media described at length and in number by Guirard \& Snell (1981) omit chelating agents as such, and must rely on the presence of casein hydrolysate, yeast extract (itself a source of metals), Tris buffer, phosphates and other components for metal ion chelation. Sometimes it is recommended that trace element concentrates be prepared in acid to ensure the solubility of metal ions, but what happens when such a solution is added to the bulk of the medium at $\mathrm{pH} 7$ ?

A defined medium for fission yeast (Edinburgh minimal medium; Mitchison, 1970) relies on citrate for metal chelation, but a number of other recipes for yeast media contain no identifiable chelator. Thus the commercially available (Difco) Wickerham's medium (see Campbell, 1988), a defined medium for yeast described by Light \& Garland (1971) used for metal-limitation studies in a chemostat, and a more recent description of 'GO' minimal medium for budding yeast (Rickwood $e t$ al., 1988) include no specific chelator. The relatively low $\mathrm{pH}$ of media for fungi would be expected to alleviate, in part, metal limitation.

In our experience, several media and their constituent trace element solutions described in the literature cannot be prepared or autoclaved without formation of a visible precipitate, which must indicate the insolubility of at least a part of the metal ion complement. Which fraction of the trace element 'solution' should be used? Under such circumstances, especially when an aim is to reproduce the growth conditions described by others, it may be prudent to adopt such unsatisfactory media, since 'improving' the medium by adding a chelator may markedly influence the growth pattern and physiology of the culture. But why should less attention be paid to $\mathrm{pFe}$ or $\mathrm{pCu}$ than to $\mathrm{pH}$ ?

Apart from solubilizing metal ions, chelating agents in media widen the margin between adequacy of supply of metal ions and their toxicity in unchelated media. Hutner (1972) cites the example of potential copper toxicity from its presence in peptones, sea water and commercial grade chemicals. Chelators can also be used to advantage when collecting aqueous samples for microbiological analysis by preventing injury to the organisms from contaminating metals (Domek et al., 
1984). On the other hand, chelators themselves can be toxic. For example, the growth of Legionella pneumophila in a defined medium is very sensitive to inhibition by EDTA, citrate or 2,2'-bipyridyl, but inhibition is reversed by the addition of compounds of various metals (Reeves et al., 1988).

Careful consideration of the composition of the medium is also necessary in studies on metal toxicity to microbes (Hughes \& Poole, 1989). Complex ingredients of growth media, such as yeast extract, proteose peptone and amino acids, complex metal ions effectively (Ramamoorthy \& Kushner, 1975), explaining the very different metal toxicities expressed in different media. For example, in the design of a medium selective for Escherichia coli strains containing the relatively zinc(and azide-) resistant $b d$-type cytochrome oxidase, up to $10 \mathrm{~mm}-\mathrm{ZnSO}_{4}$ was required in a rich, meat extract agar (where the $\mathrm{Zn}^{2+}$ was strongly complexed), or in a phosphate-rich defined medium (where the $\mathrm{Zn}^{2+}$ was precipitated as phosphate), whereas in a medium low in inorganic phosphate $0.2 \mathrm{~mm}-\mathrm{ZnSO}_{4}$ was adequate. Similar results were observed for other metal ions (Poole et el., 1989). Environmental constituents such as clays and sediment also modify metal toxicity when they are present, by adsorbing the metal species (see Gadd \& Griffiths, 1978), as will dead cells.

However, it should not be thought that wholly inorganic media are ideal for toxicity studies! Their composition has to be considered carefully. Indeed, trace metals may be removed from growth media in metallimitation studies by precipitation as insoluble hydroxides, phosphates, sulphides or carbonates (Pirt, 1975; Hughes \& Poole, 1989). Thus, Fe(III) hydroxide is precipitated in Tris/succinate growth medium, $\mathrm{pH} 8$, as Tris does not complex Fe(III) strongly enough to prevent this occurring. This explains why Neilands (1980) recommends this medium for growth of enteric bacteria in severely iron-deficient conditions. Similarly, it is not surprising that phosphate protects against the toxic effects of a range of metals, carbonate against lead, fluoride against aluminium, and chloride against cadmium. The lethal effects of cobalt and zinc are decreased in media prepared with hard water. The presence of $\mathrm{Mg}^{2+}$ protects against the toxicity of $\mathrm{Ni}^{2+}$, as shown in the enhanced toxicity of $\mathrm{Ni}^{2+}$ in lake water compared to sea water.

The complexing properties of buffers in medium (Tris, citrate and phosphate) has been commented upon. Other, so-called 'Good buffers' (Good et al., 1986) often exhibit 'negligible' metal-binding properties: examples include the sulphonic acids MES, $\mathrm{p} K_{\mathrm{a}}=6 \cdot 15$; PIPES, $\mathrm{p} K_{\mathrm{a}}=6.80 ;$ TES, $\mathrm{p} K_{\mathrm{a}}=7.5 ;$ and HEPES, $\mathrm{p} K_{\mathrm{a}}=7.55$ (Calbiochem, 1981). However, quantitative formation constant data for the interaction of these buffers with all the metal ions likely to be present in microbiological media (whether toxic or essential) are not readily available. Use of a buffer that interacts strongly with a metal cation may not only affect the bioavailability of the cation but may also result in poor control of $\mathrm{pH}$. If a significant amount of the buffer is complexed with cations the hydrogen ions will be unable to compete with metal ions for sites on the buffer and the $\mathrm{pH}$ will fall. This in turn may lead to decreased growth rates.

\section{Post-script}

It is hoped that this mini-review may make some small contribution to the arrival of that turning point in the development of 'inorganic microbiology' when attention turns from consideration of the total concentration of metal in a biological situation to an appreciation of metal speciation.

\section{References}

BaEs, C. F. \& Mesmer, R. E. (1976). The Hydrolysis of Cations. New York: Wiley.

BELLY, R. T. \& KYDD, G. C. (1982). Silver resistance in microorganisms. Developments in Industrial Microbiology 23, 567-577.

Bernhard, M., Brinckman, F. E. \& Sadler, P. J. (editors) (1986). The Importance of Chemical 'Speciation' in Environmental Processes. Berlin: Springer-Verlag.

Bird, N. P., Chambers, J. G., Leech, R. W. \& Cummins, D. (1985). A note on the use of metal species in microbiological tests involving growth media. Journal of Applied Bacteriology 59, 353-355.

CALBIOCHEM (1981). A Guide for the Preparation and Use of Buffers in Biological Systems.

Campbell, I. (1988). Culture, storage, isolation and identification of yeasts. In Yeast : a Practical Approach, pp. 1-8. Edited by I. Campbell \& J. H. Duffus. Oxford: IRL Press.

Davies, A. G. (1990). Taking a cool look at iron. Nature, London 345, 114-115.

Domer, M. J., Lechevallier, M. W., Cameron, S. C. \& McFeters, G. A. (1984). Evidence for the role of copper in the injury process of coliform bacteria in drinking water. Applied and Environmental Microbiology 48, 289-293.

Duffield, J. R. \& Williams, D. R. (1989). Chemical speciation. Chemistry in Britain 375-378.

EHRLICH, H. L. (1987). Bioleaching of silver from a mixed sulphide ore in a stirred reactor. In Biohydrometallurgy: Proceedings of the International Symposium, pp. 223-231. Edited by P. R. Norris \& D. P. Kelly.

GADD, G. M. \& Griffiths, A. J. (1978). Microorganisms and heavy metal toxicity. Microbial Ecology 4, 303-307.

Ghandour, W., Hubbard, J. A., Deistung, J., Hughes, M. N. \& PoOlE, R. K. (1988). The uptake of silver ions by Escherichia coli K12: toxic effects and interaction with copper ions. Applied Microbiology and Biotechnology 28, 559-565.

Good, N. E., Winget, G. D., Winter, W., Connolly, T. N., IzaWa, S. \& SingH, R. M. M. (1966). Hydrogen ion buffers for biological research. Biochemistry 5, 467-474

GuiraRd, B. M. \& SNELl, E. E. (1981). Biochemical factors in growth. In Manual of Methods for General Microbiology, pp. 80-111. Washington, DC: American Society for Microbiology.

GuY, R. D \& Ross-Kean, A. (1980). Algae as a chemical species monitor - a comparison of algal growth and computer calculated speciation. Water Research 14, 891-899. 
Hughes, M. N. \& Poole, R. K. (1989). Metals and Micro-organisms. London: Chapman \& Hall.

HUTNER, S. H. (1972). Inorganic nutrition. Annual Review of Microbiology 26, 313-346.

KRULL, I. S. (1986). Analysis of inorganic species by ion chromatography and liquid chromatography. In The Importance of Chemical 'Speciation' in Environmental Processes, pp. 579-612. Edited by M. Bernhard, F. E. Brinckman \& P. J. Sadler. Berlin: Springer-Verlag.

LIGHT, P. A. \& GARLAND, P. B. (1971). A comparison of mitochondria from Torulopsis utilis grown in continuous culture with iron, ammonium, magnesium or phosphate as the growth-limiting nutrient. Biochemical Journal 124, 123-134.

LUND, W. (1986). Electrochemical methods and their limitations for the determination of metal species in natural waters. In The Importance of Chemical 'Speciation' in Environmental Processes, pp. 533-561. Edited by M. Bernhard, F. E. Brinckman \& P. J. Sadler. Berlin: Springer-Verlag.

MaCLeOd, R. A., Kuo, S. C. \& Gelinas, R. (1967). Metabolic injury to bacteria. Journal of Bacteriology 93, 961-969.

Martin, J. H., Gordon, R. M. \& FitzWATER, S. E. (1990). Iron in Antarctic waters. Nature, London 345, 156-158.

May, P. M. \& Williams, D. R. (1981). Complex speciation for absorption and excretion. In Trace Element Metabolism in Man and Animals, pp. 149-151. Edited by M. C. Howell and others. Canberra: Australian Academy of Sciences.

Mitchison, M. (1970). Physiological and cytological methods for Schizosaccharomyces pombe. Methods in Cell Physiology 4, 131-165.

Morrison, G. M. P., Batley, G. E. \& Florence, T. M. (1989). Metal speciation and toxicity. Chemistry in Britain 791-795.

NeILANDS, J. B. (1980). Microbial metabolism of iron. In Iron in Biochemistry and Medicine II, pp. 529-572. Edited by A. Jacobs \& M. Worwood. London: Academic Press.

NiLsson, J. R. (1981). Effects of copper on phagocytosis in Tetrahymena. Protoplasma 109, 359-370.

Onishi, H., Kobayashi, T., Morita, N. \& Baba, M. (1984). Effect of salt concentration on the cadmium tolerance of a moderately halophilic cadmium-tolerant Pseudomonas sp. Agricultural and Biological Chemistry 48, 2441-2448.

PEARSON, R. G. (1963). Hard and soft acids and bases. Journal of the American Chemical Society 85, 3533-3539.

PIRT, S. J. (1975). Principles of Microbe and Cell Cultivation. Oxford: Blackwell.

Poole, R. K., Williams, H. D., Downie, J. A. \& Gibson, F. (1989). Mutations affecting the cytochrome $d$-containing oxidase complex of Escherichia coli $\mathrm{K} 12$ : identification and mapping of a fourth locus, cydD. Journal of General Microbiology 135, 1865-1874.
Pooley, F. D. (1982). Bacteria accumulate silver during leaching of sulphide ore minerals. Nature, London 296, 642-643.

RAMAMOORTHY, S. \& KUSHNER, D. J. (1975). Binding of mercuric and other heavy metal ions by microbial growth media. Microbial Ecology 2, 162-176.

Reeves, M. W., Pine, L., Huttner, S. H., George, J. R. \& HarRell, W. K. (1988). Metal requirements of Legionella pneumophila. Journal of Clinical Microbiology 13, 688-695.

Rickwood, D., Dujon, B. \& Darley-Usmar, V. M. (1988). Yeast mitochondria. In Yeast : a Practical Approach, pp. 185-254. Edited by I. Campbell \& J. H. Duffus. Oxford: IRL Press.

RingBom, A. (1963). Complexation in Analytical Chemistry. New York: Wiley.

Sillen, L. \& Martell, A. E. (1971). Stability Constants. Special Publication no. 25, Royal Society of Chemistry, London.

Silverman, M. P. \& Lundgren, D. G. (1959). Studies on the chemoautotrophic iron bacterium Ferrobacillus ferrooxidans. I. An improved medium and a harvesting procedure for securing high cell yields. Journal of Bacteriology 77, 642-647.

Stumm, W. \& BilinSKI, H. (1972). Trace metals in natural waters; difficulties of interpretation arising from our ignorance on their speciation. In Advanced Water Pollution Research, pp. 39-52. Edited by S. H. Jenkins. Oxford: Pergamon Press.

Sugio, T., TANo, T. \& ImaI, K. (1981). Isolation and some properties of silver ion-resistant iron-oxidizing bacterium Thiobacillus ferrooxidans. Agricultural and Biological Chemistry 45, 2037-2051.

SUNDA, W. G. \& Lewis, J. A. M. (1978). Effect of complexation by natural organic ligands on the toxicity of copper to a unicellular alga Monochrysis lutheri. Limnology and Oceanography 23, 870-876.

TREVORS, J. T. (1987). Silver resistance and accumulation in bacteria. Enzyme and Microbial Technology 9, 331-333.

Tuovinen, O. H., Puhakka, J., Hiltunen, P. \& Dolan, K. M. (1985) Silver toxicity to ferrous iron and pyrite oxidation and its alleviation by yeast extract in cultures of Thiobacillus ferrooxidans. Biotechnology Letters 7, 389-394.

WEAST, R. C. (1978). Handbook of Chemistry and Physics, 59th edn. Boca Raton: CRC Press.

Yanagimoto, M., SaItoh, H. \& Kakimoto, N. (1983). Alkaline shift effect on the uptake of germanium by algae, Chlorella ellipsoidea Oscillatoria sp. and Spirulina platensis. Journal of Fermentation Technology 61, 233-238.

Zevenhuizen, L. P. T. M., Dolfing, J., Eshuis, E. J. \& ScholtenKoERSELMaN, I. J. (1979). Inhibitory effects of copper on bacteria related to the free ion concentration. Microbial Ecology 5, 139 146. 